\title{
A single-center experience of sorafenib monotherapy in patients with advanced intrahepatic cholangiocarcinoma
}

\author{
TING-TING PAN ${ }^{1,2^{*}}$, WEI WANG ${ }^{3 *}$, WEI-DONG JIA ${ }^{1,2}$ and GE-LIANG XU $\mathrm{U}^{1,2}$ \\ ${ }^{1}$ Department of Hepatic Surgery, Affiliated Provincial Hospital of Anhui Medical University; \\ ${ }^{2}$ Anhui Province Key Laboratory of Hepatopancreatobiliary Surgery; ${ }^{3}$ Department of Medical Oncology, \\ Affiliated Provincial Hospital of Anhui Medical University, Hefei, Anhui 230001, P.R. China
}

Received September 29, 2015; Accepted January 26, 2017

DOI: $10.3892 / \mathrm{ol} .2017 .5847$

\begin{abstract}
Patients with advanced intrahepatic cholangiocarcinoma (ICC) have a poor prognosis and the therapeutic options available for treating ICC are limited. Sorafenib, a multikinase inhibitor of vascular endothelial growth factor receptor 2 and 3, platelet derived growth factor receptor- $\beta$, B-Raf proto-oncogene, serine/threonine kinase and C-Raf proto-oncogene, serine/threonine kinase, is a novel reference standard for the treatment of advanced hepatocellular carcinoma. Sorafenib has previously been demonstrated to exhibit significant antitumor activity in various cholangiocarcinoma cell lines and in xenograft ICC models. The present study aimed to assess the efficacy and safety of sorafenib as a single-agent treatment in patients with advanced ICC. Eligible patients were administere no prior therapy for metastatic or unresectable disease. Sorafenib was administered orally at a dose of $400 \mathrm{mg}$ twice daily continuously. The primary endpoint was considered as the disease control rate (DCR) at 12 weeks. Secondary endpoints included time to progression (TTP), progression-free survival (PFS), overall survival (OS), duration of treatment (DOT) and the adverse event profile. A total of 15 patients were enrolled in the present study, with a median DOT of 3.2 months (range, 1.5-30 months). A total of 4 patients achieved a partial response and 7 patients achieved stable disease, with a DCR of $73.3 \%$. The median OS time was 5.7 months [95\% confidence interval (CI), 5.0-6.4], the PFS time was 5.5 months (95\% CI, 3.9-7.1) and the median TTP was 3.2 months (range, 1.5-29 months). The most common toxicity
\end{abstract}

Correspondence to: Professor Ge-Liang Xu or Dr Wei-Dong Jia, Department of Hepatic Surgery, Affiliated Provincial Hospital of Anhui Medical University, 17 Lujiang Road, Hefei, Anhui 230001, P.R. China

E-mail: xugeliang2013@163.com

E-mail: jwd1968@sina.com

${ }^{*}$ Contributed equally

Key words: sorafenib, intrahepatic cholangiocarcinoma, advanced, toxicity was a skin rash, which wlas observed in 5 patients (33.3\%). Grade 3 hand-foot syndrome was observed in 1 patient (6.7\%), which required treatment termination. The results of the present study suggest that sorafenib monotherapy may exhibit promising anticancer activity in patients with advanced ICC and that it has a manageable toxicity profile.

\section{Introduction}

Intrahepatic cholangiocarcinoma (ICC) is the second most common type of primary liver malignancy, accounting for $5-10 \%$ of all malignant liver cancer cases $(1,2)$. Patients with ICC often have a poor prognosis due to a difficult early diagnosis, a high degree of malignancy and a poor therapeutic efficacy. Surgical resection is currently the only potential curative therapy for ICC, but the majority of patients often present at an advanced stage and are therefore not amenable to surgical resection. A previous study reported that even when patients received radical surgery, the 1-, 3- and 5-year survival rates were $35-86,20-52$ and $20-40 \%$, respectively (3-5). A widely used conventional treatment for patients with advanced ICC is chemotherapy. However, the response rates to numerous chemotherapeutic agents are poor or non-existent given the fact that ICC is a highly aggressive tumor that often displays resistance to chemotherapy $(3,6)$. The efficacy of cytotoxic drugs, including 5-fluoropyrimidines, gemcitabine, cisplatin/oxaliplatin, mitomycin $\mathrm{C}$, doxorubicin, docetaxel and irinotecan, have been investigated, with low response rates of $0-36 \%$ and a median survival times of between 4.5 and 14.8 months (7-12). Previous studies have indicated that combined chemotherapy can increase the response rate and survival time, but typically, the response rate remains low with a higher toxicity incidence $(13,14)$. Thus, the development of more effective therapies for patients with advanced ICC is warranted.

Sorafenib (Nexavar/Bay43-9006; Bayer AG, Leverkusen, Germany) is a multi-targeted small molecule that inhibits the activity of vascular endothelial growth factor receptor (VEGFR) 2 and 3, platelet-derived growth factor receptor (PDGFR), fibroblast growth factor and RAF proto-oncogene, serine/threonine kinase, thus inhibiting tumor proliferation and angiogenesis (15). Sorafenib has demonstrated safety and efficacy against a wide variety of cancer types in numerous 
preclinical and clinical studies, and has been approved for the treatment of renal cell and hepatocellular carcinoma (16). However, limited data are available on the use of sorafenib in patients with advanced ICC. In the current study, the efficacy and tolerability of sorafenib in patients with advanced ICC was evaluated.

\section{Materials and methods}

Eligibility criteria. Patients eligible for the present study had a cytologically or pathologically confirmed diagnosis of ICC that was surgically unresectable or metastatic, and excluded combined hepatocellular carcinoma and cholangiocarcinoma. Measurable disease was required with no prior therapy. Previous chemotherapy, radiation therapy, transcatheter arterial chemoembolization or other local treatments were permitted only when the size of the measurable lesions had increased by $>25 \%$, and it must have been completed $\geq 4$ weeks prior to enrollment. Patients were $>18$ years old, had an expected lifespan of $>12$ weeks and an Eastern Cooperative Oncology Group (ECOG) (17) performance status of 0-2. In addition, patients had adequate liver and renal function tests with a total bilirubin level $\leq 2$ times the upper limit of the normal level, AST or ALT levels $\leq 2$ times the upper limit of the normal level, a serum creatinine level of $<2 \mathrm{mg} / \mathrm{dl}$ and a creatinine clearance rate of $\geq 60 \mathrm{ml} / \mathrm{min}$. Requirements also included adequate bone marrow function, as indicated by an absolute neutrophil count of $\geq 1,500 / \mathrm{mm}^{3}$, a platelet count of $\geq 60 \times 10^{9} / 1$, a hemoglobin level of $\geq 8.0 \mathrm{~g} / \mathrm{dl}$, an International Normalized Ratio of $\leq 2.3$ or a prothrombin time prolonged by $\leq 6 \mathrm{sec}$.

The present study was approved by the Human Research Ethics Committee of Anhui Medical University (Hefei, China) and written informed consent was obtained from all patients.

Study design. The present study was a single-arm open-label exploratory study whose primary aim was the evaluation of single-agent sorafenib activity, defined as the control rate at 12 weeks, in patients with advanced ICC. The disease control rate (DCR) was defined as the percentage of patients that exhibited no disease progression [complete response (CR), partial response (PR) and stable disease (SD)] but who remained under treatment at 12 weeks. Secondary endpoints included time to progression (TTP), progression-free survival (PFS), overall survival (OS), duration of treatment (DOT) and the adverse event profile. TTP was defined as the time between the first day of administration of sorafenib and confirmed disease progression upon imaging. PFS was defined as the time between the first day of administration of sorafenib and confirmed disease progression upon imaging or mortality due to any cause. OS was defined as the time between the first day of sorafenib administration and mortality or last contact.

Treatment plan. Sorafenib (Nexavar/Bay43-9006; Bayer AG, Leverkusen, Germany) was administered at a fixed dose of $400 \mathrm{mg}$ twice a day continuously in a 3-week cycle until disease progression, intolerant drug-associated toxicity, the necessity for cessation of the medication or withdrawal of patient consent occurred.
Doses were delayed or reduced in cases of possible associated hematological or non-hematological toxicity graded according to the National Cancer Institute Common Terminology Criteria for Adverse Events (NCI CTCAE; version 4.0) (18). Sorafenib was taken orally at the following predefined dose levels: Level-1, $400 \mathrm{mg}$ every $12 \mathrm{~h}$; level-2, $400 \mathrm{mg}$ every day; and level-3, $400 \mathrm{mg}$ every other day. In the case of G1-G2 hematological and non-hematological toxicity, no dose modification or delay was planned. For G3 hematological toxicity, treatment was continued with a dose reduction of one dose level. For G4 hematological and G3 nonhematological toxicity, treatment was delayed until toxicity resolution to G1-G2, and a dose reduction of one level was planned. In the case of G4 non-hematological toxicity, treatment was terminated. Patients requiring treatment interruption for $>1$ month or requiring a reduction of $>2$ dose levels were removed from treatment unless it was considered clinically beneficial.

Disease assessment. Baseline evaluation included medical history, physical examination, pathological ICC diagnosis and tumor assessment using computed tomography (CT) or magnetic resonance imaging (MRI) according to the Response Evaluation Criteria in Solid Tumors (RECIST; version 1.1) (19) within 28 days of study entry.

Patients were contacted and interviewed every 3 weeks within the first 3 months after the start of treatment. Disease assessment included determination of vital signs, ECOG performance status, blood routine, liver and renal function, coagulation function, accompanying treatment and adverse effects. The interval between follow-ups could be prolonged to 6 weeks after the first 3 months. Tumor response was evaluated every 6 weeks using CT or MRI. Lifetime follow-up was to be conducted every 3 months and telephone follow-up was allowed (Fig. 1).

Toxicity assessment. Patients were evaluated for treatment-associated toxicity in each cycle for the first 12 weeks and every two cycles thereafter according to the NCI CTCAE.

Statistical analysis. The primary endpoint of the trial was taken as the DCR $(\mathrm{CR}+\mathrm{PR}+\mathrm{SD}$, according to the RECIST criteria) at 12 weeks. Second endpoints included TTP, OS, DFS, DOT and safety. Survival analysis was performed using the Kaplan-Meier method. All statistical analyses were performed using SPSS software (version 17.0; SPSS Inc., Chicago, IL, USA).

\section{Results}

Patient characteristics and treatment administration. A total of 15 patients with pathologically confirmed diagnosis of ICC were enrolled for the present study over a period of 24 months (Fig. 2; Table I). The median age was 53 years (range, 39-65 years), with 8 males and 7 females. All patients had a good ECOG performance status of 0-1 prior to sorafenib administration. A total of 10 patients had received previous treatment; 4 had received radical surgery (all with tumor recurrence following surgery) and 6 had received palliative surgery or biopsy. Overall, 1 patient received radiotherapy and 1 received chemotherapy following surgery. 


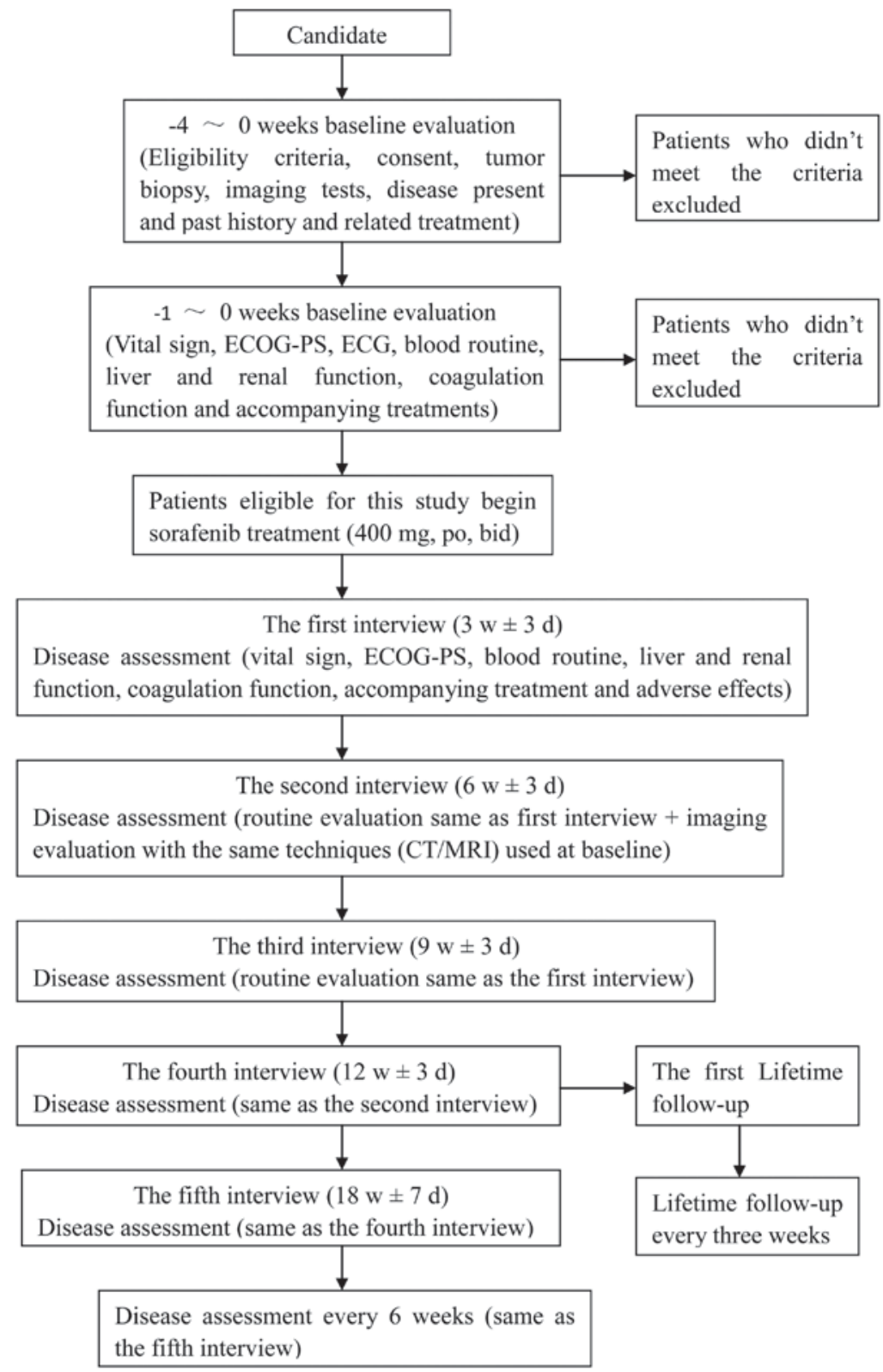

Figure 1. Diagram of the disease assessment for the patients with intrahepatic cholangiocarcinoma. CT, computed tomography; MRI, magnetic resonance imaging; ECOG-PS, Eastern Cooperative Oncology Group-performance status; ECG, electrocardiogram; po, bid; taken orally, twice daily.
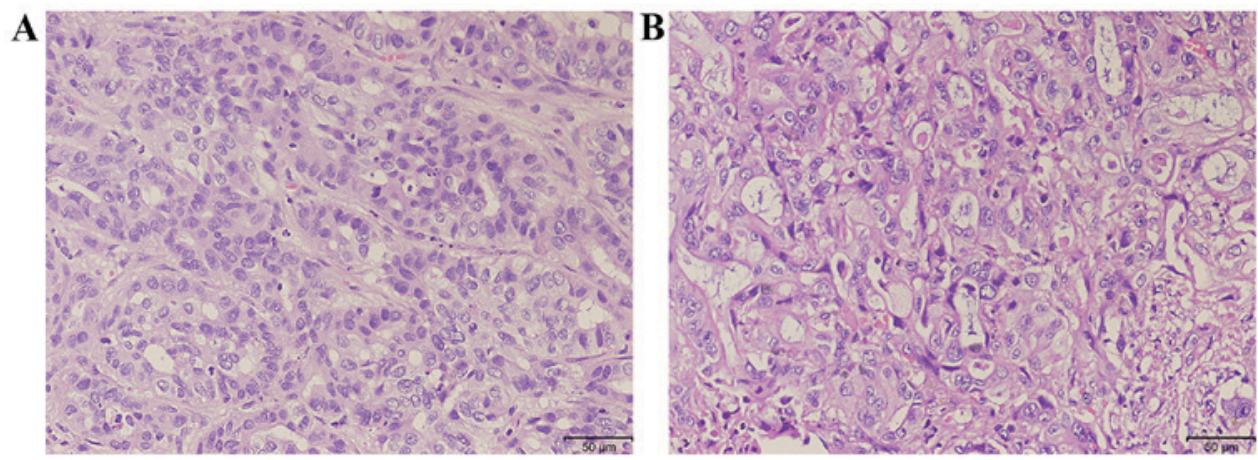

Figure 2. Representative histopathological examination of two patients with intrahepatic cholangiocarcinom with hematoxylin and eosin staining. (A) Invasive moderately-differentiated adenocarcinoma. (B) Poorly-differentiated adenocarcinoma.

The median DOT was 3.2 months (range, 1.5-30 months). Sorafenib was discontinued in 14 patients due to tumor progression in 4 patients $(26.7 \%)$, intolerance to an adverse event in 1 patient (6.7\%), mortality in 2 patients $(13.3 \%)$ and 
Table I. Clinicopathological characteristics of patients $(n=15)$ with intrahepatic cholangiocarcinoma.

\begin{tabular}{|c|c|}
\hline Clinicopathological characteristic & Value \\
\hline \multicolumn{2}{|l|}{ Age, years } \\
\hline Median & 53 \\
\hline Range & $39-65$ \\
\hline \multicolumn{2}{|l|}{ Gender, n (\%) } \\
\hline Male & $8(53.3)$ \\
\hline Female & $7(46.7)$ \\
\hline \multicolumn{2}{|l|}{ ECOG performance status, n (\%) } \\
\hline 0 & $12(80.0)$ \\
\hline 1 & $3(20.0)$ \\
\hline \multicolumn{2}{|l|}{ Macrovascular invasion, $\mathrm{n}(\%)$} \\
\hline Present & $4(26.7)$ \\
\hline Absent & $11(73.3)$ \\
\hline \multicolumn{2}{|l|}{ Extrahepatic tumor metastasis, n (\%) } \\
\hline Present & $9(60.0)$ \\
\hline Absent & $6(40.0)$ \\
\hline \multicolumn{2}{|l|}{ Extent of disease, n (\%) } \\
\hline Liver & $15(100.0)$ \\
\hline Lymph nodes & $9(60.0)$ \\
\hline Lung & $1(6.7)$ \\
\hline Soft tissue & $3(20.0)$ \\
\hline \multicolumn{2}{|l|}{ Previous treatment, n (\%) $10(66.7)$} \\
\hline Surgery & $10(66.7)$ \\
\hline Radical & $4(26.7)$ \\
\hline Palliative/biopsy & $6(40.0)$ \\
\hline Radiotherapy after surgery & $1(6.7)$ \\
\hline Chemotherapy after surgery & $1(6.7)$ \\
\hline
\end{tabular}

ECOG, Eastern Cooperative Oncology Group.

liver failure in 7 patients $(46.7 \%)$. By the time the follow-up of the study ended (July 2014), only 1 patient (6.7\%) remained on sorafenib treatment.

Efficacy. Following sorafenib monotherapy, 4 patients achieved a partial response and 7 patients achieved a stable disease status, with a DCR of $73.3 \%$ at 12 weeks (Table II). Among the 4 patients who achieved a partial response, 1 patient succumbed with an inferior OS time of 4.2 months. As illustrated in Fig. 3, the CT scan image at 8 and 12 weeks post-sorafenib treatment demonstrated that the tumor had developed liquefactive necrosis and was less viable. The patient subsequently succumbed to liver failure induced by hepatic portal tumor compression. As illustrated in Fig. 4, another patient who presented with unresectable ICC due to portal and inferior vena cava invasion achieved a partial response following sorafenib treatment. The patient had received sorafenib treatment for 15 months and remained on sorafenib treatment. The median OS time for all patients was 5.7 months [range, 2.2-32.5 months; 95\% confidence interval
Table II. Therapeutic efficacy of sorafenib inn patients with intrahepatic cholangiocarcinoma.

\begin{tabular}{lcr}
\hline Response & Cases, $\mathrm{n}$ & Rate, $\%$ \\
\hline Complete response & 0 & 0.0 \\
Partial response & 4 & 26.7 \\
Stable disease & 7 & 46.7 \\
Progressive disease & 4 & 26.7 \\
Disease control rate & 11 & 73.3 \\
Total & 15 & 100.0 \\
\hline
\end{tabular}

(CI), 5.0-6.4] and the median PFS time was 5.5 months (range, 1.5-32.5 months; 95\% CI, 3.9-7.1), as illustrated in Fig. 5. The median TTP was 3.2 months (range, 1.5-29 months).

Toxicity. All patients were assessed for toxicity. There were no treatment-associated mortalities. As illustrated in Table III, the main adverse effects of sorafenib included skin rashes, hand-foot syndrome, diarrhea, nausea/vomiting, liver enzyme and bilirubin elevation, and fatigue. G1-2 toxicity was observed in 8 patients $(53.3 \%)$ while G3-4 toxicity was observed in 1 patient $(6.7 \%)$. The most common toxicity was a skin rash, which was present in 5 patients (33.3\%). A single patient exhibited G3 toxicity in the form of hand-foot syndrome toxicity. Hematological toxicity was not identified in any patients.

\section{Discussion}

Few treatment options are available for ICC, and the prognosis of affected patients is extremely poor. Advanced ICC poses a significant therapeutic challenge for multiple reasons, including a low radical resection rate, the limited efficacy of cytotoxic chemotherapy and the rarity of the disease, leading to difficulties in conducting large randomized studies (20-25). Novel effective therapeutic approaches are required in order to improve the treatment outcome of patients with ICC.

Sorafenib is an oral multikinase inhibitor with existing approval for the treatment of metastatic renal cell and advanced hepatocellular carcinoma. Furthermore, sorafenib has been demonstrated to exhibit significant antitumor activity in various cholangiocarcinoma cell lines and in xenograft ICC models (26-28). The mechanism underlying the effects of sorafenib may involve the ability to simultaneously inhibit tumor angiogenesis (via VEGF and PDGF signaling pathways) and tumor cell survival (via Ras/Raf/MEK/ERK1/mitogen activated protein kinase-2 kinase, and signal transducer and activator of transcription 3-dependent signaling pathways) $(27,29)$. Owing to the molecular alterations described in ICC, the present study aimed to investigate the efficacy of sorafenib as a single agent in patients with advanced ICC. The DCR at 12 weeks was defined as the primary endpoint, which is considered a suitable endpoint in oncology when a non-cytotoxic agent is used, and a low objective response and high SD rate is expected (30).

At the intention-to-treat analysis, the response and SD rates were 26.7 , and $46.7 \%$, respectively, with a DCR of $73.3 \%$. The median PFS and OS times were 5.5, and 5.7 months, respectively. In a previous phase II study on sorafenib treatment as 


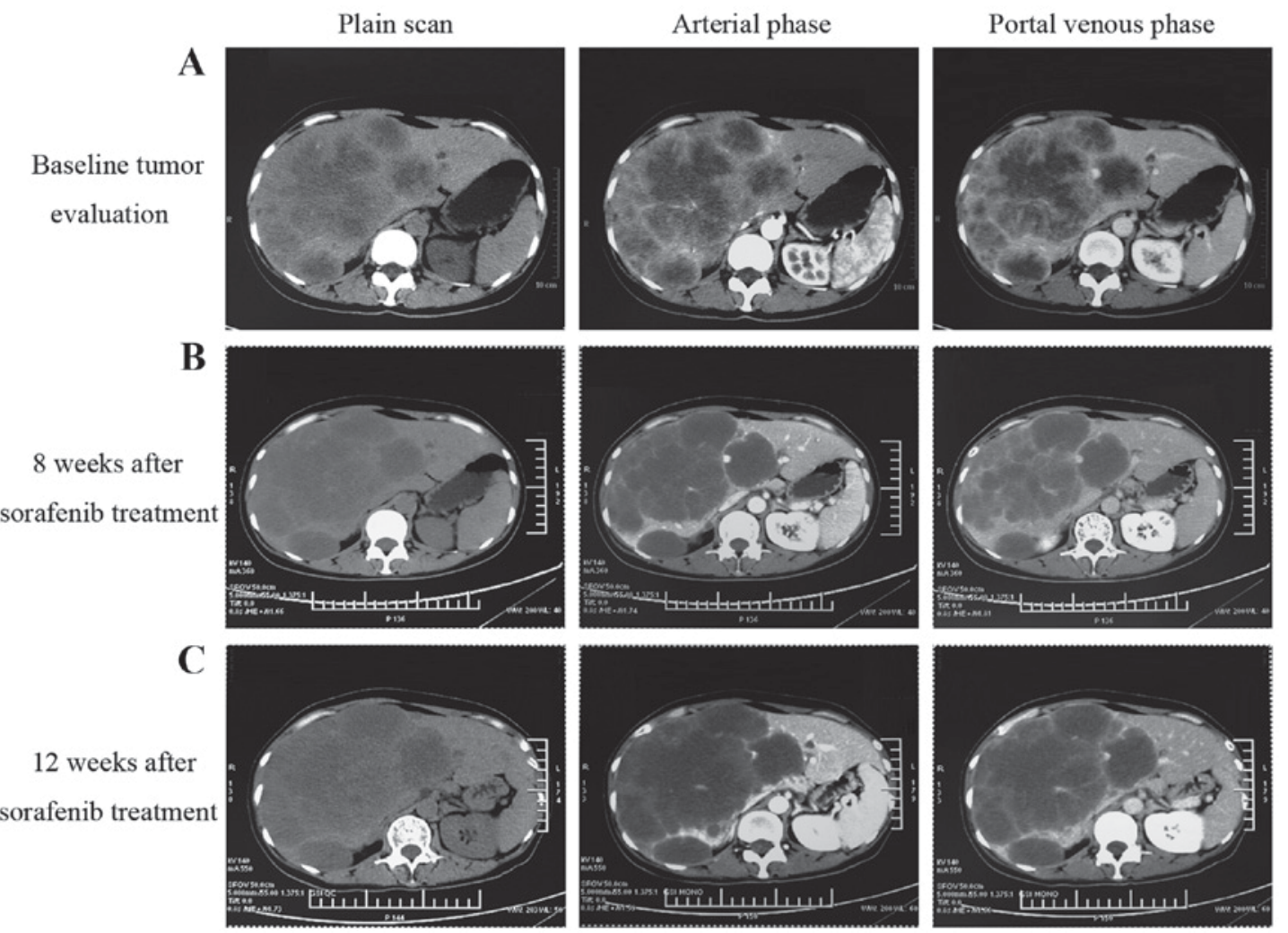

Figure 3. Radiological tumor evaluation of a patient with intrahepatic cholangiocarcinoma during sorafenib treatment. (A) The baseline tumor evaluation CT scan image. (B) The imaging evaluation CT scan at 8 weeks following sorafenib treatment demonstrating tumor liquefactive necrosis. (C) CT scan at 12 weeks post-sorafenib treatment demonstrating larger necrotic areas and a less viable tumor. CT, computed tomography.

a single agent in 46 patients with advanced biliary tract carcinoma, an objective response rate of $2 \%$ and a DCR at 12 weeks of $32.6 \%$ were reported. In addition, the median PFS and OS times were 2.3 , and 4.4 months, respectively (31). One possible explanation for the inferior survival outcomes reported in this study is that $56 \%$ of patients had $\geq 1$ prior lines of chemotherapy prior to enrollment. In the present study, 1 patient who received combined chemotherapy following surgery experienced PFS and OS times of 6 months. Another patient who received radiotherapy following surgery experienced worse PFS and OS times of 2.2 months. A previous phase II study on gemcitabine and cisplatin combined with sorafenib in patients with advanced biliary adenocarcinomas demonstrated that the addition of sorafenib to gemcitabine and cisplatin in biliary adenocarcinomas did not improve efficacy compared with previous data, and showed that toxicity was increased (32). However, a previous comprehensive review summary stated that a combination of sorafenib with cytotoxic agents is generally well tolerated (33). In addition, several phase I and II studies have demonstrated that the combination of sorafenib with cytotoxic agents in several solid tumor types, including hepatocellular carcinoma, melanoma, and gastric, colorectal, breast and ovarian cancer, achieved promising results (33). However, limited data are available on the combination of sorafenib with chemotherapeutic agents or radiotherapy in patients with ICC. Studies into the effect of a combination of sorafenib with cytotoxic drugs therapy or radiotherapy on advanced ICC are warranted.

A previous phase II trial that used sorafenib as a first-line treatment for advanced cholangiocarcinoma and gallbladder cancer failed to demonstrate a clinically significant objective response (34). A confirmed response rate of $0 \%$ and a DCR of $39 \%$ were reported. In addition, the patients experienced a median PFS time of 3 months and a median OS time of 9 months (34). It has been noted that the response rate and survival outcomes appear to be different among patients with gallbladder carcinoma vs. intrahepatic cholangiocarcinoma vs. extrahepatic cholangiocarcinoma (35); the limitation of this study was the incorporation of all biliary cancer types into one group, irrelevant of the site of origin. The molecular changes associated with biliary tract adenocarcinoma development and progression was poorly defined, and it is unclear whether suggested location-associated differences in pathogenesis can influence clinical behavior and patient prognosis. However, a study on 128 patients who underwent resection for biliary cancer indicated that biliary tract cancer exhibits differential expression of cell cycle regulatory proteins according to the tumor site of origin and morphology, demonstrating different survival outcomes (36). Thus, the response rate and survival outcomes may be different due to location-associated differences in molecular changes. To the best of our knowledge, the present study was the first to investigate the efficacy of sorafenib in patients with ICC, and it achieved promising response rates.

The toxicity profile of sorafenib in the present study was manageable. Toxicities observed were primarily grades 1 and 2 . The most common toxicity was a skin rash in 5 patients $(33.3 \%)$. A previous study on the effects of sorafenib in patients with hepatocellular carcinoma reported an improved response in patients with early skin reactions (37). However, the same correlation 

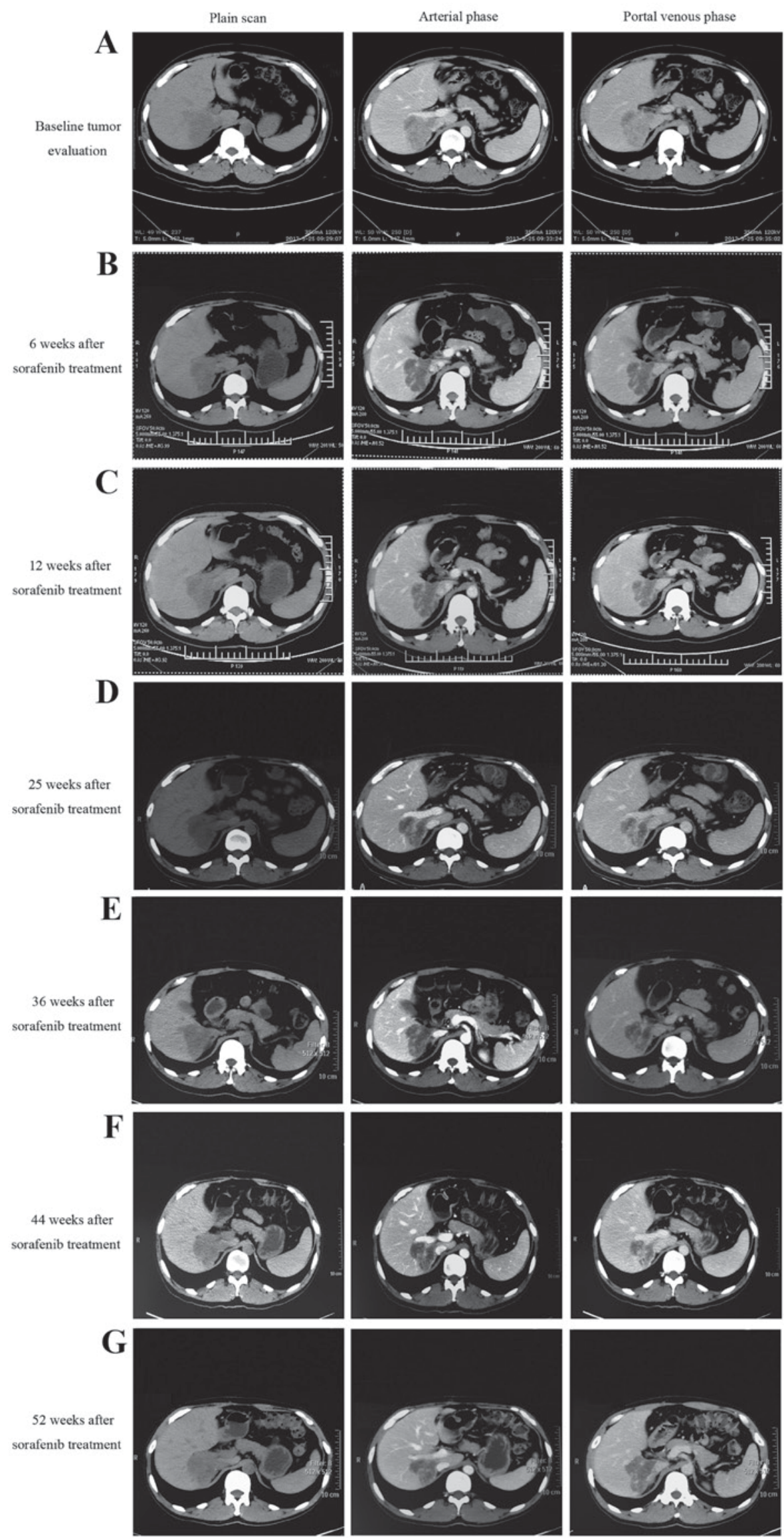

Figure 4. Radiological tumor evaluation of a patient with intrahepatic cholangiocarcinoma during sorafenib treatment. (A) Baseline tumor evaluation showing a tumor of $7 \times 6 \mathrm{~cm}$ in size. (B) Local tumor necrosis following 6 weeks of sorafenib treatment. (C) Local tumor necrosis with a decreased tumor size $(5 \times 4 \mathrm{~cm})$ following sorafenib treatment for 12 weeks. CT evaluation following sorafenib treatment for (D) 25 weeks (tumor size, $5 \times 4 \mathrm{~cm}$ ), (E) 36 weeks, (F) 44 weeks and $(\mathrm{G}) 52$ weeks. 
Table III. Treatment-associated toxicities following sorafenib treatment in patients with intrahepatic cholangiocarcinoma.

\begin{tabular}{lccc}
\hline Toxicity & $\begin{array}{c}\text { G1-G2, } \\
\text { n (\%) }\end{array}$ & $\begin{array}{c}\text { G3-G4, } \\
\text { n }(\%)\end{array}$ & $\begin{array}{c}\text { Total, } \\
\text { n }(\%)\end{array}$ \\
\hline Bilirubin elevation & $2(13.3)$ & $0(0.0)$ & $2(13.3)$ \\
Skin rash & $5(33.3)$ & $0(0.0)$ & $5(33.3)$ \\
Hand-foot syndrome & $2(13.3)$ & $1(6.7)$ & $3(20.0)$ \\
Diarrhea & $2(13.3)$ & $0(0.0)$ & $2(13.3)$ \\
Nausea/vomiting & $3(20.0)$ & $0(0.0)$ & $3(20.0)$ \\
Liver enzyme elevation & $2(13.3)$ & $0(0.0)$ & $2(13.3)$ \\
Fatigue & $4(26.7)$ & $0(0.0)$ & $4(26.7)$ \\
Total & $8(53.3)$ & $1(6.7)$ & $9(60.0)$ \\
\hline
\end{tabular}

A

Progression-free Survival

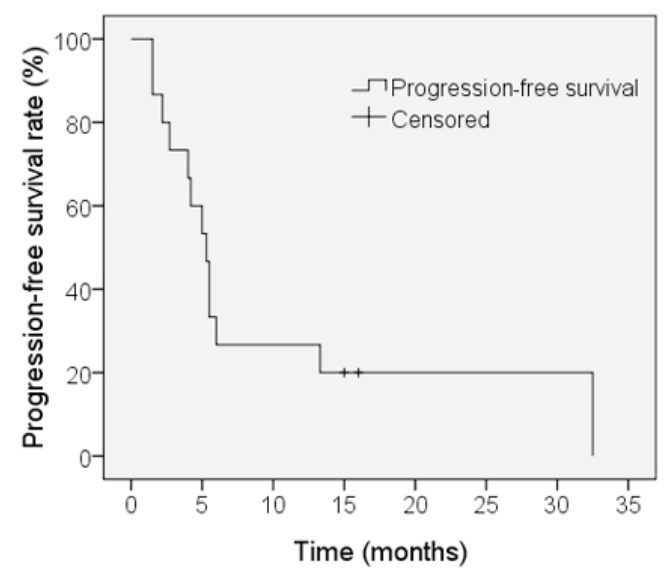

B

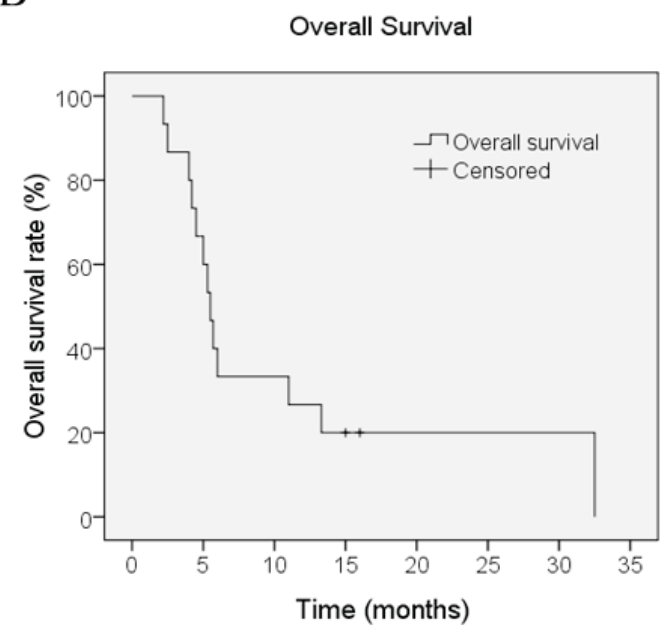

Figure 5. (A) Progression-free survival and (B) overall survival for patients with intrahepatic cholangiocarcinoma treated with the single-agent sorafenib $(\mathrm{n}=15)$.

was not established in the current study. Grade 3 hand-foot syndrome was observed in 1 atient $(6.7 \%)$ and hematological toxicity was not identified in any patients. The safety profile of sorafenib in the present study is acceptable in comparison with that observed in patients treated with chemotherapy. Several phase II clinical trials on the effects of gemcitabine combined with cisplatin in patients with advanced biliary tract carcinoma reported grade 3-4 toxicity in 33-75\% of patients $(13,38,39)$.

One limitation of the present study was that it was a single institute study with a small sample size. The results indicate the requirement for a multiple center phase II or III clinical trial with a large sample size.

In conclusion, the results of the present study have provided the first evidence that sorafenib is generally well tolerated and active in patients with advanced ICC. In order to enhance the treatment efficacy of sorafenib, further trials focused on the effects of sequential or combination therapy are warranted, as patients eventually develop progressive disease when on sorafenib or cannot tolerate the treatment. Correlative studies to define predictive molecular markers for sorafenib are required.

\section{Acknowledgements}

The abstract was presented at the 8th Annual Meeting of Chinese College of Surgeons and the 19th Annual Meeting of the European Society of Surgery, May 15-17, 2015, in Beijing, China, and was previously published in European Surgery, May 2015, Volume 47, Supplement 1, p1-281.

\section{References}

1. Casavilla FA, Marsh JW, Iwatsuki S, Todo S, Lee RG, Madariaga JR, Pinna A, Dvorchik I, Fung JJ and Starzl TE: Hepatic resection and transplantation for peripheral cholangiocarcinoma. J Am Coll Surg 185: 429-436, 1997.

2. Jemal A, Bray F, Center MM, Ferlay J, Ward E and Forman D: Global cancer statistics. CA Cancer J Clin 61: 69-90, 2011.

3. Morise Z, Sugioka A, Tokoro T, Tanahashi Y, Okabe Y, Kagawa T and Takeura C: Surgery and chemotherapy for intrahepatic cholangiocarcinoma. World J Hepatol 2: 58-64, 2010.

4. Tan JC, Coburn NG, Baxter NN, Kiss A and Law CH: Surgical management of intrahepatic cholangiocarcinoma-a population-based study. Ann Surg Oncol 15: 600-608, 2008.

5. Paik KY, Jung JC, Heo JS, Choi SH, Choi DW and Kim YI: What prognostic factors are important for resected intrahepatic cholangiocarcinoma? J Gastroenterol Hepatol 23: 766-770, 2008.

6. Skipworth JR, Keane MG and Pereira SP: Update on the management of cholangiocarcinoma. Dig Dis 32: 570-578, 2014.

7. Okusaka T, Ishii H, Funakoshi A, Yamao K, Ohkawa S, Saito S, Saito $\mathrm{H}$ and Tsuyuguchi T: Phase II study of single-agent gemcitabine in patients with advanced biliary tract cancer. Cancer Chemother Pharmacol 57: 647-653, 2006.

8. Penz M, Kornek GV, Raderer M, Ulrich-Pur H, Fiebiger W, Lenauer A, Depisch D, Krauss G, Schneeweiss B and Scheithauer W: Phase II trial of two-weekly gemcitabine in patients with advanced biliary tract cancer. Ann Oncol 12: 183-186, 2001

9. Hezel AF and Zhu AX: Systemic therapy for biliary tract cancers. Oncologist 13: 415-423, 2008.

10. Ducreux M, Van Cutsem E, Van Laethem JL, Gress TM, Jeziorski K, Rougier P, Wagener T, Anak O, Baron B and Nordlinger B; EORTC Gastro Intestinal Tract Cancer Group: A randomised phase II trial of weekly high-dose 5-fluorouracil with and without folinic acid and cisplatin in patients with advanced biliary tract carcinoma: Results of the 40955 EORTC trial. Eur J Cancer 41: 398-403, 2005.

11. Eckel F and Schmid RM: Chemotherapy in advanced biliary tract carcinoma: A pooled analysis of clinical trials. Br J Cancer 96: 896-902, 2007.

12. Chen JS, Lin YC, Jan YY and Liau CT: Mitomycin C with weekly 24-h infusion of high-dose 5-fluorouracil and leucovorin in patients with biliary tract and periampullar carcinomas. Anticancer Drugs 12: 339-343, 2001. 
13. Valle J, Wasan H, Palmer DH, Cunningham D, Anthoney A, Maraveyas A, Madhusudan S, Iveson T, Hughes S, Pereira SP, et al: Cisplatin plus gemcitabine versus gemcitabine for biliary tract cancer. N Engl J Med 362: 1273-1281, 2010.

14. Hsu C, Shen YC, Yang CH, Yeh KH, Lu YS, Hsu CH, Liu HT, Li CC, Chen JS, Wu CY and Cheng AL: Weekly gemcitabine plus 24-h infusion of high-dose 5-fluorouracil/leucovorin for locally advanced or metastatic carcinoma of the biliary tract. $\mathrm{Br}$ J Cancer 90: 1715-1719, 2004.

15. Wilhelm SM, Carter C, Tang L, Wilkie D, McNabola A, Rong H, Chen C, Zhang X, Vincent P, McHugh M, et al: BAY 43-9006 exhibits broad spectrum oral antitumor activity and targets the RAF/MEK/ERK pathway and receptor tyrosine kinases involved in tumor progression and angiogenesis. Cancer Res 64 7099-7109, 2004.

16. Di Marco V, De Vita F, Koskinas J, Semela D, Toniutto P and Verslype C: Sorafenib: From literature to clinical practice. Ann Oncol 24 (Suppl 2): ii30-ii37, 2013.

17. Oken MM, Creech RH, Tormey DC, Horton J, Davis TE, McFadden ET and Carbone PP: Toxicity and response criteria of the Eastern Cooperative Oncology Group. Am J Clin Oncol 5: 649-655, 1982

18. Basch E, Reeve BB, Mitchell SA, Clauser SB, Minasian LM, Dueck AC, MendozaTR, Hay J, Atkinson TM, Abernethy AP, et al: Development of the national cancer institute's patient-reported outcomes version of the common terminology criteria for adverse events (PRO-CTCAE). J Natl Cancer Inst 106. pii: dju244 2014.

19. Eisenhauer EA, Therasse P, Bogaerts J, Schwartz LH, Sargent D, Ford R, Dancey J, Arbuck S, Gwyther S, Mooney M, et al: New response evaluation criteria in solid tumours: Revised RECIST guideline (version 1.1). Eur J Cancer 45: 228-247, 2009.

20. Patel T: Increasing incidence and mortality of primary intrahepatic cholangiocarcinoma in the United States. Hepatology 33 $1353-1357,2001$

21. Altekruse SF, McGlynn KA and Reichman ME: Hepatocellular carcinoma incidence, mortality, and survival trends in the United States from 1975 to 2005. J Clin Oncol 27: 1485-1491, 2009.

22. Mosconi S, Beretta GD, Labianca R, Zampino MG, Gatta G and Heinemann V: Cholangiocarcinoma. Crit Rev Oncol Hematol 69: 259-270, 2009

23. Anderson CD, Pinson CW, Berlin J and Chari RS: Diagnosis and treatment of cholangiocarcinoma. Oncologist 9: 43-57, 2004.

24. Pattanathien P, Khuntikeo N, Promthet S and Kamsa-Ard S: Survival rate of extrahepatic cholangiocarcinoma patients after surgical treatment in Thailand. Asian Pac J Cancer Prev 14: 321-324, 2013

25. Jarnagin WR, Fong Y, DeMatteo RP, Gonen M, Burke EC, Bodniewicz BS J, Youssef BA M, Klimstra D and Blumgart LH: Staging, resectability, and outcome in 225 patients with hilar cholangiocarcinoma. Ann Surg 234: 517-519, 2001.

26. Kim DH, Jeong YI, Chung CW, Kim CH, Kwak TW, Lee HM and Kang DH: Preclinical evaluation of sorafenib-eluting stent for suppression of human cholangiocarcinomacells. Int J Nanomedicine 8: 1697-1711, 2013
27. Sugiyama H, Onuki K, Ishige K, Baba N, Ueda T, Matsuda S, Takeuchi K, Onodera M, Nakanuma Y, Yamato M, et al: Potent in vitro and in vivo antitumor activity of sorafenib against human intrahepatic cholangiocarcinoma cells. J Gastroenterol 46: 779-789, 2011.

28. Wang C, Maass T, Krupp M, Thieringer F, Strand S, Wörns MA, Barreiros AP, Galle PR and Teufel A: A systems biology perspective on cholangiocellular carcinoma development: Focus on MAPK-signaling and the extracellular environment. J Hepatol 50: 1122-1131, 2009.

29. Blechacz BR, Smoot RL, Bronk SF, Werneburg NW, Sirica AE and Gores GJ: Sorafenib inhibits signal transducer and activator of transcription-3 signaling in cholangiocarcinoma cells by activating the phosphatase shatterproof 2. Hepatology 50: 1861-1870, 2009.

30. Adjei AA, Christian M and Ivy P: Novel designs and end points for phase II clinical trials. Clin Cancer Res 15: 1866-1872, 2009.

31. Bengala C, Bertolini F, Malavasi N, Boni C, Aitini E, Dealis C, Zironi S, Depenni R, Fontana A, Del Giovane C, et al: Sorafenib in patients with advanced biliary tract carcinoma: A phase II trial. Br J Cancer 102: 68-72, 2010

32. Lee JK, Capanu M, O'Reilly EM, Ma J, Chou JF, Shia J, Katz SS, Gansukh B, Reidy-Lagunes D, Segal NH, et al: A phase II study of gemcitabine and cisplatin plus sorafenib in patients with advanced biliary adenocarcinomas. Br J Cance 109: 915-919, 2013.

33. Dal Lago L, D'Hondt V and Awada A: Selected combination therapy with sorafenib: A review of clinical data and perspectives in advanced solid tumors. Oncologist 13: 845-858, 2008.

34. El-Khoueiry AB, Rankin CJ, Ben-Josef E, Lenz HJ, Gold PJ, Hamilton RD, Govindarajan R, Eng C and Blanke CD: SWOG 0514: A phase II study of sorafenib in patients with unresectable or metastatic gallbladder carcinoma and cholangiocarcinoma. Invest New Drugs 30: 1646-1651, 2011.

35. Nathan H, Pawlik TM, Wolfgang CL, Choti MA, Cameron JL and Schulick RD: Trends in survival after surgery for cholangiocarcinoma: A 30-year population-based SEER database analysis. J Gastrointest Surg 11: 1488-1497, 2007.

36. Jarnagin WR, Klimstra DS, Hezel M, Gonen M, Fong Y, Roggin K, Cymes K, DeMatteo RP, D'Angelica M, Blumgart LH and Singh B: Differential cell cycle-regulatory protein expression in biliary tract adenocarcinoma: Correlation with anatomic site, pathologic variables, and clinical outcome. J Clin Oncol 24: 1152-1160, 2006

37. Vincenzi B, Santini D, Russo A, Addeo R, Giuliani F, Montella L, Rizzo S, Venditti O, Frezza AM, Caraglia M, et al: Early skin toxicity as a predictive factor for tumor control in hepatocellular carcinoma patients treated with sorafenib. Oncologist 15: 85-92, 2010.

38. Thongprasert S, Napapan S, Charoentum C and Moonprakan S: Phase II study of gemcitabine and cisplatin as first-line chemotherapy in inoperable biliary tract carcinoma. Ann Onco 16: 279-281, 2005.

39. Weigt $\mathbf{J}$ and Malfertheiner P: Cisplatin plus gemcitabine versus gemcitabine for biliary tract cancer. Expert Rev Gastroenterol Hepatol 4: 395-397, 2010. 